\title{
HOX Transcript Antisense RNA
}

National Cancer Institute

\section{Source}

National Cancer Institute. HOX Transcript Antisense RNA. NCI Thesaurus. Code

C116287.

HOX transcript antisense RNA ( 2 kb) is encoded by the human HOTAIR gene. This noncoding RNA plays a role in the repression of HOXD genes. 